theory, indicating, as they do, an instability of the nervous system. It is curious that the extent of the paralysis in both cases is almost identical--the same side affected, at the same occupation, and the same history of previous chorea. Unfcrtunately there is no record of the mental state of either patient just before the attack, as it would have added much interest to the cases ; but as neither can throw any light upon their thoughts at this time any speculation would be useless.

That the thumb in Case I has remained partially paralysed may be accounted for by supposing that the special artery to the thumb centre (such a centre is recog nized) has remained in a state of spasm for a longer period and produced a weakness of the ganglia by insufficient nourishment. In Case II the theory of spasm is very greatly supported by the intense headaches, the great complaint of the patient being, "Give me something for my head." I have been unable to find any record of simila cases, and so can quote no authorities upon the causation of this strange affection.

\section{TWO CASES OF TETANUS}

\section{TREATED BY SUBDURAL INJECTIONS OF MAGNESIUM SULPHATE.}

BY OLIVER SMITHSON, F.R.C.S.I.,

MEDICAL SCPERINTENDENT, MOUNT MORGAN GENERAL HOSPITAL, OUIFENSIAND.

As this form of treatment may be said to be in the trial stage, the following notes may be of interest.

\section{CASE I.}

On September 28th, 1911, Ronald R., aged 9 years, complained af feeling ill, and did not go to school. The following morning, as his condition was unchanged, the parents called in Dr. Morris, of Mount Morgan. Just after the doctor arrived the patient had a violent tetanic seizure, and was ordered to the hospital. He a violent tetanic seizure, and was ordered to the hospital. He
was admitted at 1 p.m., the temperature then being $99.4^{\circ}$ and the palse 112 .

The boy had been in the habit of running about barefoot, and there were several small cuts and abrasions on both feet. The iodine, and a gauze dressing applied. Although the patient lived some miles out in the bush he had no further convulsions during his journey to hospital.

As soon as the wound had been dressed the boy was put to bed and 1,500 units of antitetanic serum (P. D. and Co.'s) given subcutaneously. At 3 p.m. the patient had a tetanic seizure which lasted two or three minutes; risus sardonicus was well marked, and from this time on there was great difficulty in opening the mouth.

Similar attacks occurred at 4 p.m. and at 5.15 p.m., and a second dose of 1,500 units of serum was then given. The temperature had risen to $100.2^{\circ}$. The attacks now recurred with perature had risen to 100.2 . The attacks now recurred

At 2.30 a.m. I injected a third dose of 1,500 units of serum and under chloroform anaesthesia punctured the spinal canal and under chloroform anaesthesia punctured the spinal canal $2.5 \mathrm{c} . \mathrm{cm}$. of cerebro-spinal fluid, and slowly injected in its place 2.5 c.cm. of cerebro-spinal fluid, and slowly injected in its place a. like amount of sterile 25 per cent. solution of magnesium
sulphate. A small pustule had developed in the sole of one sulphate. A small pustule had developed in the sole of one foot, and I excised the surrounding tissue and swabbed with pure carbolic acid. In this tissue I subsequently identified wounded his foot with a rusty nail some days before, and this was probably the site of the wound.

After the injection of the magnesium sulphate the patient slept quietly for an hour, and then quite suddenly the breathing became embarrassed, and the temperature fell to $97^{\circ}$. As the breathing became steadily worse, a small hypodermic of strychnine was given, and repeated in half an hour's time. The boy's condition distinctly improved, and he took liquid nourishment well.

At 10 a.m. on September 30 th the temperature rose rapidly to $104.6^{\circ}$; cold sponging was resorted to, and the temperature fell to $100^{\circ}$. The boy slept all the afternoon, and seemed on the high road to recovery, until the early hours of October 1st, when the temperature again rose to $104^{\circ}$. Cold sponging now had no effect on the temperature, and the breathing again became very embarrassed. Strychnine was administered and oxygen given, but the boy's condition gradually became worse and he died at $10.40 \mathrm{a.m}$, the temperature immediately before death being $107^{\circ}$.

From the moment the magnesium sulphate was injected to the time of the boy's death no trace of tetanic spasm occurred.

The dose recommended is 1 c.cm. of a 25 per cent. solution for every $25 \mathrm{lb}$. body weight, but from the effect of the drug in this case I am inclined to think this dosage too large.
CASE II.

On November 9th, 1911, Vera H., aged 8 years, whilst running about barefoot, cut her foot on a stone. The wound was treated at home until November $22 n d$, when the child, who appeared to be out of sorts, was brought to the hospital.

On admission temperature and pulse were normal. The foot was soaked for twenty minutes in 1 in 4,000 solution of mercury perchloride, and then dressed with a borfc acid fomentation.

The patient was put to bed and slept well all night, but at 7 a.m. on November 23 rd she had slight muscular twitchings 7 a.m. on November 23 rd she had slight muscular twitchings and complained of pain in the back and of difticulty in opening the mouth; 1,500 units of antitetanic serum were given subcutaneously, and the wound on the foot swabbed with tincture
of iodine. Five grains of potassium bromide were given every of iodine.

The muscular twitchings continued at intervals all dav, and The muscular twitchings continued at intervals all day, and the temperature rose steadily until at 5 p.m. it had reached
$104^{\circ}$. Under chloroform anaesthesia I injected 1,500 units of $104^{\circ}$. Under chloroform anaesthesia I injected 1,500 units of
antitetanic serum into the subdural space, having previously withdrawn an equal quantity of cerebro-spinal fluid.

The tetanic symptoms persisting, I gave a hypodermic injection of 1 grain of morphine. As the bladder was becoming distended, the catheter was passed, $20 \mathrm{oz}$. of urine being withdrawn. The patient passed a restless night, and the following morning $(6.30 \mathrm{a} . \mathrm{m}$.$) , under chloroform anaesthesia, I injected$ $1 \mathrm{c.cm}$. of a 25 per cent. sterile solution of magnesium sulphate into the subdural space.

This procedure was followed by a distinct improvement, and the muscular spasms ceased until noon, when they recurred with increased violence and frequency. A second bypodermic injection of morphine was given with great benefit, the child becoming quieter, getting a fair amount of sleep, and taking becoming quieter,

At 10 p.m. the convulsions returned, the attacks coming on At 10 p.m. the convulsions. returned, the attacks coming on
about every hour till 4 a.m., when they ceased, and the child
slept till 7 a.m. Severe attacks of tonic and clonic convulsions slept till $7 \mathrm{a} . \mathrm{m}$. Severe attacks of tonic and clonic convulsions More morphine was given, but had no effect.

At 4 p.m. a frightful attack of convulsions took place, the body being violently jerked about the bed, and death ensued ten minutes later.

The patient suffered from retention of urine the whole time she was in hospital, and the catheter was passed as required. During the forty-eight hours preceding death the temperature was high, and cold sponging was resorted to frequently, and death the temperature rose to $108.2^{\circ}$.

From the above notes it will be seen that magnesium sulphate used in this way is a particularly potent drug and to find the correct dosage seems to me to be the great difficulty. The two patients were about the same age and weight, and I feel sure that the dose administered in the first case was too big, whilst I fear I erred on the other side in the second case.

We see a good deal of tetanus in this part of Queens. land, and from my own experience I am inclined to think the above treatment is the one most likely to bring a case to a successful issue.

\section{A SUPPOSED CASE OF HEAT-STROKE :} REMARKABLE RECOVERY.

\section{BY ALEXANDER STOREY ST. JOHN, M.R.C.S.ENG., L.R.C.P.LOND.,} ELTHAM, KENT.

THE following case seems to me a most notable one, and, as far as my experience goes, is quite unique. It presents many difficulties with regard to the exact pathological condition that was involved, also as to the diagnosis.

A man, aged 53, was crossing a road during one of the hottest days of last summer, when he suddenly found himself on the ground, with a" horse's hoof right on top of him" ; this was his description of what happened. He picked himself up and ran across the road to his son, who was waiting for him on the pavement, and who brushed the dust off his clothes. He com. plained of no poin or discomfort of any kind, but his son took him into chemist's shop where he as given nto a chemist's shop, where he was given a dose of sal-volatile. He then went home by train (a distance of eight miles), scot down and made a good tea, feeling quite well all the time. Towards the end of this meal he became a "little queer," went upstairs and felt very ill indeed, and remembered nothing afterwards. This attack came on about five hours after he had fallen down in th

half an hour later.
I found his condition extremely grave ; he had vomited prcfusely, was very pale, slightly conscious, with cold and clammy sweat, a slow regular pulse of fairly good volume, pupils reacting to light, and conjunctival reftex present. I was told that he had been much worse before I came, and hat been quite unconscious.

I had him placed in bed, and after hearing his recent history, carefully examined him for signs of injuries, but beyond a 
bruise on each elbow there were none. The head showed no sign whatever of any injury. The patient gradually recovered consciousness. Three days subsequently he seemed to be progressing favourably, and complained of nothing beyond slight giddiness and some headache, which he did not seem to localize particularly. He ate and slept well, his pulse and temperature were normal, the bowels open, and urine passed freely. I considered him to be going on very well, indeed practically out of danger, and informed his friends to that effect. On the fourth day, however, he became partially unconscious; he still took his food well; the bladder and rectum acted naturally, all the retlexes, superficial and deep, were normal, as were the optic reflexes, superficial and deep, were normal, as were the optic discs, and there was no paralysis of either limbs or speech; the
urine contained no sugar or albumen. I called Dr. F. $S$. Toogood of Lewisham in consultation, and we gave a hopeful prognosis. Coma, however, gradually increased, and he became prognosis. Coma, however, gradually increased, and he became actually unconscious; his breathing, which up to now

quiet, was stertorous; he could still swallow a little.

As the patient's condition looked very serious, I asked Sir D. Ferrier to see him with me. At that time the patient passed both urine and faeces unconsciously, and he was unable to swallow. There were slight twitchings of the muscles of both upper extremities, and occasionally of the lips. The pulse remained steany and regular at about 70 , and the temperature ranged between $99^{\circ}$ and $100^{\circ}$

The next day Mr. Ballance saw the patient with me; he advised withdrawal of cerebro-spinal fluid from the lumbar region, and drew off under pressure $110 z$ of very slishtly redregion, and drew off under pressure $1 \frac{1}{2} \mathrm{oz}$. of very slightly redconscious, and his state seemed hopeless; his temperature had gone up to $104^{\circ}$.

During the five hours after the aspiration the patient During the five hours after the aspiration the patient gradually became conscious, and within twelve hours he was talking, taking nourishment, and quite able to understand everything that was sait to him. The deep, superficial and
conjunctival reflexes, which had been absent, all returned. conjunctival reflexes, which had been absent, all returned. most difficult to overcome.

For the next three days the patient appeared to be going on very well, but on the fourth day after the aspiration I noticed that he was gradually again lapsing into a state of insensibility, with symptoms of paralysis; he vomited twice, and there was less of power of deglutition. Mr. Ballance again visited the patient, and performed a second aspiration in the same neighbourhood, drawing off a similar amount of cerebro-spinal fluid of the same appearance as before. Again within five hours the patient began to show signs of returning consciousness, and at the end of twelve hours he was quite sensible, able to talk, and take food by the mouth. From that time he never retrograded, and has made an excellent recovery; he subsequently graded, and has made an excellent recovery ; he subsequently went to the seaside, and now-se

appears to be in his ordinary health. room as cool as possible. The head was shaved and surrounded with ice-bags. The room had large blocks of ice standing in trays, and an electric fan was kept going continuously. The spray from a garden-hose was kept plying on an adjoining roof, and by so doing prevented the reflected heat-rays from radiating into the room. By these means we were enabled to keop the temperature of the room at $60^{\circ}$, whilst the temperature in the shade outside was about $90^{\circ}$.

I have known the patient intimately for the last twelve years, and beyond the fact that I removed some glands from his neck five years ago, he has always enjoyed excellent health, with no organic disease of any kind. A few weeks before the illness he passed as a first-class life for insurance purposes, but on that occasion he was not examined by me. He came to see me about three weeks prior to this attack, complaining of headache and giddiness, accompanied by slight epistaxis. These symptoms I attributed to the excessive heat, and on keeping him as quiet and cool as possible they passed off. To complicate the diagnosis there was the history of a hurt, and the question arose whether he became suddenly unconscious and fell down in the road, or whether he was knocked down by a cab. However this may be, there was no visible injury to the head, and as he immediately rose up and walked to the railway station there would not appear to be any serious $r \in$ sult due to a fall or other possible accident.

My opinion is that he had a sudden heat-stroke and feil down as a consequence of that, the heat being excessive (between $80^{\circ}$ and $90^{\circ}$ in the shade), and he had passed the morning in the somewhat violent exercise of running up and down stairs and walking about large warehouses. He is a total abstainer and non-smoker, his arteries were in an exceedingly good condition for his age, with no symptoms whatever of atheroma, and there was no increase of blood pressure. I think the existence of intracranial tumour nay be excluded in this case, there being no prolonged pressure symptoms beyond the coma. It was at one time thought to be a case of haemorrhage affecting the cerebral cortex; but, although there was slight twitch. ing of the arms, this soon passed away, and there was no motor paralysis.
The remarkable recovery in a few hours from what appeared to be imminent death, on two occasions, after the withdrawal of the cerebro-spinal fluid, seems to rather point to the fact that he was suffering from what might n a sense be described as a "blistering of his cerebral cortex," caused by the excessive heat rays of the sun (a meningo-cortical oedema), and that the fluid was being excreted faster than it could drain away, and by removing the excess a drain was established, and thus the pressure was relieved.

\section{ACUTE ANTERIOR POLIOENCEPHALOMYELITIS IN SOUTH STAFFORDSHIRE.}

By L. S. TOMKYS, L.R.C.P., M.R.C.S.,

MEDICAL OFFICER OF HEALTH, RURAL DISTIICT OF LICHFIELD.

THE following cases of poliomyelitis which came under my observation during July and August will probably be of interest, in view of the prominence which has recently been given to this disease in its epidemic form. Six of the cases occurred in my own practice, and the seventh was under the care of Captain Bagshawe, R.A.M.C., to whom I am indebted for details and for permission to include it. Five of the cases occurred in the village of Whittington in five separate families, and two (in one family) in a semi-detached cottage about a mile away, the building being an isolated one.

CASE I.-Male, aged 1 year and 4 months, seemed feverish on evening of July lst, but little notice was taken of this. The next morning it was apparent that the right leg was partially paralysed. This would seem to have been the first case.

CASE II.-Male, aged 6 years. The date of onset is doubtful, CASE II.-Male, aged 6 years. The date of onset is doubtful,
but it was some time between Cases I and III. The boy was feverish one night and two days later it was noticed that the feverish one night and two days later it was noticed that the right leg was partially paralysed. No doctor was called in, and the cases, the child was quite well, with the exception of a slight limp.

CASE III.-Male, aged 13 years, had a typical attack of measles about July 8th. He was out four days after the rash appeared. His brother had measles a fortnight before. On July 15 th he appeared to be unwell, but there was nothing definite. On July 18th he apparently had pain in the head, whicl was retracted. The temperature was subnormal, the pulse rapid, the pupils equal but rather large. He was constipated. He had lost the use of both arms, but could move the hands.

CASE IV.-Male, aged $2 \frac{1}{4}$ years. On July 21 st had headache and feverishness, and next morning it was noticed that the movements of the left leg were impaired.

CASE v.-Aged l1 year (under the care of Captain Bagshawe R.A.M.C.). The child was first seen on July 21 st, when it was R.A.M.C.). The child was first seen on July 2lst, when it was and tenderness of both legs. The following day there was complete paralysis of both legs from the hips down.

CASE vi.-Male, aged 1 year and 7 months, was sick on August 28th and quite helpless on August 29th. There was retraction of the head and loss of use in both arms from shoulder to elbow.

CASE VII.-Male, aged $2 \frac{1}{2}$ years (brother to VI), lost the use of both legs on August 29th, but had been tired and sleepy for about a week previously.

Both these children had suffered from summer diarrhoea.

Whittington, in which five of the cases occurred, is a small village about three miles from Lichfield, and, although the sanitary arrangements naturally leave much to be desired, they are certainly no worse, if anything rather better, than the average. Not being situated near a main road, rapid traffic is scarce, and the village was singularly free from dust, considering the dryness of the summer. The house in which Cases vr and vir occurred is situated in a field close to a by-road.

The water supply is obtained from the South Staffordshire Waterworks Company by the houses in the village, the remaining house being supplied by a well.

Cases II and III had the same milk supply, but the others each had a separate one. The Whittington cases were in the centre of the village, and within a circle with a radius of about 100 yards ; the houses were fairly clean and not overcrowded. None are situated near a stable.

It is difficult to trace the origin of the outbreak, as the first child to suffer had never been away from home, and no visitors had been to the house. The child partook of ordinary food, and the only animal on the establishment was a cat. There may, of course, have been abortive cases before this, but I could obtain no information of such. The local veterinary surgeon (Mr. Connell) informs me that he 